Original Article

\title{
Lumbar disc disease: the effect of inversion on clinical symptoms and a comparison of the rate of surgery after inversion therapy with the rate of surgery in neurosurgery controls
}

\author{
Alexander D. Mendelow, FRCS ${ }^{1,2)^{*}}$, Barbara A. Gregson, $\mathrm{PhD}^{1)}$, \\ Patrick Mitchell, FRCS ${ }^{1,2)}$, Ian Schofield, FRCP ${ }^{2}$, Manjunath Prasad, FRCS ${ }^{3)}$, \\ Guy Wynne-Jones, PhD ${ }^{2)}$, Anant Kamat, FRCS ${ }^{2}$, Michaila Patterson ${ }^{1}$, \\ Laura Rowell, $\mathrm{BSc}^{2)}$, Gerard Hargreaves, $\mathrm{BSc}^{4)}$ \\ 1) Department of Neurosurgery, Newcastle University: CAV Westgate Road, Newcastle upon Tyne NE4 \\ $5 P L, U K$ \\ 2) Department of Neuroscience, Royal Victoria Infirmary, UK \\ 3) Department of Neurosurgery, James Cook Hospital Middlesbrough, UK \\ 4) Department of Physiotherapy, Northumberland College of Arts and Technology, UK
}

\begin{abstract}
Purpose] We have previously shown inversion therapy to be effective in a small prospective randomised controlled trial of patients with lumbar disc protrusions. Our purpose now was to measure symptoms and to compare the surgery rate following inversion for 85 participants with the surgery rate in 3 control groups. [Participants and Methods] Each of the 85 inverted participants acted as their own control for the "symptomatic" part of the study. In the "Need for surgery" part of the study, one control group was made up of similar patients with leg pain and sciatica who were referred to the same clinic in the same year. Two additional control groups were examined: the original control group from the pilot trial and the lumbar disc surgery waiting list patients. [Results] Inversion therapy relieved symptoms: there were improvements in the Visual Analogue Score, Roland Morris and Oswestry Disease indices and Health Utility Score compared with their pre-treatment status. Also, the 2 year surgery rate in the inversion participants in the registry $(21 \%)$ was significantly lower than in the matched control group (39\% at two years and $43 \%$ at four years). It was also lower than the surgery rate in the other 2 control groups. [Conclusion] Inversion therapy relieved symptoms and avoided surgery.

Key words: Inversion therapy, Lumbar disc protrusion, Sciatica
\end{abstract}

(This article was submitted May 7, 2021, and was accepted Aug. 2, 2021)

\section{INTRODUCTION}

We have previously shown that inversion therapy reduced the need for surgery in patients with lumbar disc protrusions ${ }^{1)}$. Low back pain is now the 4th most common cause of Disability Associated Life Years (DALYs) in the 25 to 49 year old age group $^{2)}$ and it has become even more common over the last decade ${ }^{3)}$. Low Back Pain (LBP) is its commonest main manifestation but sciatica is associated with the worst prognosis ${ }^{4}$. Reports of the prevalence of sciatica vary from $1-43 \%{ }^{5)}$. Physical reduction in the size of the lumbar disc protrusion (LDP) may relieve the sciatica. This may be achieved with disc distraction therapy (inversion or traction), natural resolution and healing, or with surgical excision which is performed in more than 15,000 adult patients in the United Kingdom annually and this figure has doubled in 10 years ${ }^{6}$. The cost of backpain and its

*Corresponding author. Alexander D. Mendelow (E-mail: amendelow@gmail.com)

(C)2021 The Society of Physical Therapy Science. Published by IPEC Inc.

(c) (i) $\odot$ This is an open-access article distributed under the terms of the Creative Commons Attribution Non-Commercial No DerivaCC BY NC ND tives (by-nc-nd) License. (CC-BY-NC-ND 4.0: https://creativecommons.org/licenses/by-nc-nd/4.0/) 
treatment in Europe was estimated to be almost $2 \%$ of gross national product ${ }^{7)}$.

Inversion therapy was used by Hippocrates some 2,400 years ago to treat spinal disorders ${ }^{8}$ and was subsequently described by Vidus Vidius, with reference to Hippocrates in 15449). Modern inversion therapy is achieved on an inversion table (Fig. 1).

In a prospective randomised controlled trial (PRCT), we showed that inversion therapy reduced the need for surgery in three out of four patients that had been added to a surgical discectomy waiting list in our UK NHS Hospital ${ }^{1)}$. The purpose of the current study was to evaluate the efficacy of inversion therapy in a larger cohort. We have now performed this comparative effectiveness study in patients with lumbar disc disease, referred to the same neurosurgery unit and treated initially with inversion therapy. Matched controls were identified from other referrals to the same unit. Operative surgery completion rates were then evaluated in both groups. In addition, 2 other control groups were compared: the control group from the previous $\mathrm{PRCT}^{1)}$ and the cases from the contemporaneous waiting list for surgery in the same neurosurgery unit. To evaluate the efficacy of inversion on their own symptomatology, the inversion participants each acted as their own control before, during and after inversion therapy.

\section{PARTICIPANTS AND METHODS}

This study has 2 parts: In the inversion register, each patient acted as their own control with regard to their own symptoms. In the second part of the study, the rate of surgery of the patients in the registry was compared with the rate of surgery from 3 different control groups from the same neurosurgery clinic.

Patients referred to the neurosurgery department with lumbar disc disease during 2014 were considered for this study by one of 4 (out of a dozen) consultant NHS neurosurgical staff and 102 eligible patients were referred into the study, of whom 85 met the inclusion criteria. The study administrator contacted the patients to organise an assessment appointment and five further inversion treatment appointments over a three-week period and sent them a pre-treatment self-assessment questionnaire for completion. At the initial physiotherapy assessment appointment, the study physiotherapist checked them for eligibility, took consent and started inversion treatments. Teeter inversion tables (Fig. 1) were used throughout with a minimum of two minutes' inversion repeated up to six times over a 30-minute period. Patients were inverted to the maximum tolerated angle for each patient (45 to 90 degrees head down from the horizontal). After the sixth clinic treatment, the patient was contacted to organise delivery of an inversion table to their home. They were advised to self-invert at least two or three times per day. Patients were reviewed in clinic 6 weeks later and the physiotherapy 2nd assessment was completed. Six and twelve months after recruitment, follow-up self-assessment questionnaires were sent to the patients. If these were not returned a further copy was posted and the patient was contacted by phone. Further telephone follow up was used to track the rate of surgery up to 2 years after recruitment to the registry. The rate of surgery in these registry patients was compared with 3 different control groups in the second part of the study.

Patients aged 18-75 were eligible for inclusion in the registry if they were within 6 months of a current attack of pain with a single level unilateral disc as shown on MRI and surgery was indicated. Patients were excluded if they were pregnant, had cauda equina syndrome, symptoms or signs of bladder impairment, had a progressive neurological deficit, had a history of significant cardiorespiratory disease in the last six months, had any other medical condition precluding a head down position (as defined in the protocol).

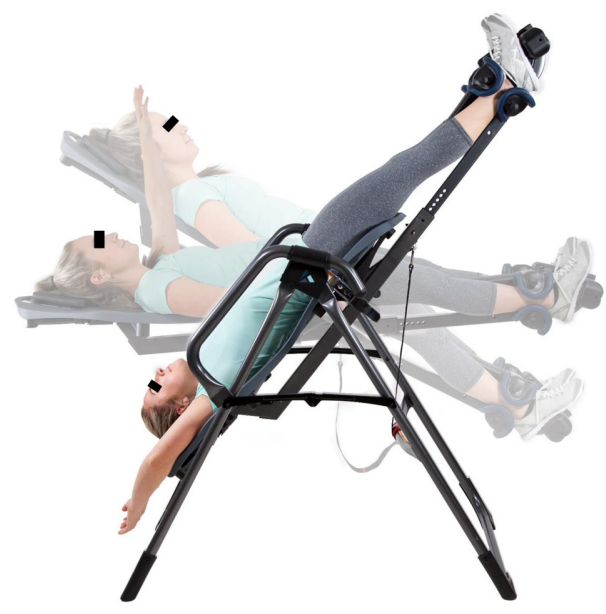

Fig. 1. Inversion using gravity on the Teeter Inversion table with the patient in 3 positions: initial (faintest), horizontal (restraint strap looped and loose) and inverted to 50 degrees from the horizontal (limited by the restraint strap becoming rigid and tight). The horizontal position is achieved with the upward stretching of one arm and the inverted position is achieved by the cranial-ward out-stretching of both arms. Return to the initial position is achieved by the return of both arms to the patient's side. The angle of inversion can be changed by adjustment of the length of the strap. Images supplied by Teeter from Teeter.com. 
The primary outcome measure was avoidance of surgery and constitutes the second part of the study. Other outcome measures were the Roland Morris Disability Questionnaire $(\mathrm{RM})^{10)}$, Oswestry Disability Index (ODI) ${ }^{11)}$, Health Utility Score ${ }^{12)}$ and a Visual Analogue Scale (VAS) of current pain. Each registry patient acted as their own control for these outcome measures.

Responses regarding these secondary outcomes in the 85 out of 102 registry patients at 12 months were used when available but if the patient did not respond at 12 months the 6 month response was used. With regard to the primary outcome of surgery, the question about whether the patient had surgery or not was ascertained from the patient in the outcome questionnaire, from the electronic hospital records or again over the telephone. The last check on whether the patient had undergone surgery or not since the study was undertaken in the spring of 2018.

To compare the inversion registry patients with matched controls, all patients, except those in the registry, who were seen in the neurosurgery clinic in 2014 with leg pain or sciatica recorded in the outpatient clinic letter were identified using a text search on the electronic record system (2,045 patients). Three different but matching cases with leg pain or sciatica of the same gender with a date of birth within two months of that of each inversion therapy registry patient were selected from these 2,045 patients and the first two of the three were selected for the study control group. The medical records were then checked by two consultant neurosurgeons (ADM and PM) to confirm the diagnoses and to obtain details of the date of onset, date of clinic visit, imaging, whether listed for surgery and to confirm the date and type of surgery. If a control was found not to be matched, the third case was then used. Sometimes only I case match could be found. Nerve root injections were not considered as definitive surgery.

To compare the inversion registry patients with a second group of controls from the neurosurgery waiting lists for lumbar spinal surgery, two data files were obtained from the same hospital (Newcastle upon Tyne NHS Foundation Trust). The first included all patients added to the neurosurgical waiting list during 2014 for the procedures shown in Table 1. For these procedures, the expected ICD 10 diagnostic codes would be M511, M512, M513. The second file contained admissions for the same patients between 01 January 2014 and 31 December 2015 (covering the recruitment year plus a 1 year follow-up period). Those admitted for surgery created the second control group.

Both files included more than one data line for some patients - this could be because they had had a cancelation and were added back on the waiting list or they could be admitted and not treated and admitted again later. The files were thus edited to provide one line per patient. This list excluded patients who were on the registry.

Numbers and percentages are reported. Changes in outcome measures are compared with baseline using paired t-tests (continuous variables), Wilcoxon signed rank tests (scaled variables) or McNemar tests (binary variables) as appropriate (Table 2). Kaplan Meier survival analysis were undertaken comparing time from the date of referral to the study, from the date seen in the clinic with the MRI scan until the date of operation or to the last time that the notes were checked or the patient contacted if there was no operation. All statistical analyses were conducted using IBM SPSS version 22.

The study was reviewed by the National Research Ethics Service Committee North West-Preston (Ref:13/NW/0757; IRAS ID 135078). Data were collected in accordance with current UK Information Governance Guidelines.

NHS Health Research Authority Approval is summarised at: www.hra.nhs.uk/planning-and-improving-research/application-summaries/research-summaries/prof-mendelow-backswing-comparative-effectiveness-research-study

All participants in the registry gave written informed consent as specified in the Ethical Approval.

Table 1. Waiting list procedures identified for database

\begin{tabular}{ll}
\hline V251 & Primary extended decompression of lumbar spine and intertransverse fusion of joint of lumbar spine \\
V252 & Primary extended decompression of lumbar spine NEC \\
V253 & Primary posterior decompression of lumbar spine and intertransverse fusion of joint of lumbar spine \\
V254 & Primary posterior laminectomy decompression of lumbar spine \\
V255 & Primary posterior decompression of lumbar spine NEC \\
V256 & Primary lateral foraminotomy of lumbar spine \\
V258 & Other specified primary decompression operations on lumbar spine \\
V259 & Primary anterior excision of lumbar intervertebral disc NEC \\
V331 & Primary laminectomy excision of lumbar intervertebral disc \\
V332 & Primary fenestration excision of lumbar intervertebral disc \\
V334 & Primary anterior excision of lumbar intervertebral disc NEC \\
V337 & Primary microdiscectomy of lumbar intervertebral disc \\
V338 & Other specified primary excision of lumbar intervertebral disc \\
V339 & Unspecified primary excision of lumbar intervertebral disc \\
V351 & Primary excision of intervertebral disc NEC \\
V671 & Primary posterior lumbar medial facetectomy \\
V672 & Primary hemilaminectomy decompression of lumbar spine \\
\hline
\end{tabular}


Table 2. Responses to self-completed questionnaires at pre-treatment and outcome including change from pre-treatment questionnaire

\begin{tabular}{|c|c|c|c|c|}
\hline & $\begin{array}{l}\text { Pre-treatment questionnaire } \\
\text { responses } \\
\mathrm{N}=77\end{array}$ & $\begin{array}{l}\text { Outcome questionnaire } \\
\text { responses } \\
\mathrm{N}=70\end{array}$ & $\begin{array}{l}\text { Change in score from } \\
\text { pre-treatment questionnaire } \\
\qquad \mathrm{N}=70\end{array}$ & $\begin{array}{c}\text { Test and } \\
\text { significance }\end{array}$ \\
\hline Visual analogue pain score & $6(4,7) 1,10$ & $3(1,5) 0,10^{* *}$ & $-2(-4,0)-9,4^{\wedge}$ & $\begin{array}{l}\text { Wilcoxon } \\
p<0.0001\end{array}$ \\
\hline Any pain medication & $56(73 \%)$ & $34(49 \%)$ & & $\begin{array}{c}\text { McNemar } \\
\mathrm{p}=0.002\end{array}$ \\
\hline Employed & $49(64 \%)$ & $48(69 \%)$ & & $\begin{array}{c}\mathrm{McNemar} \\
\mathrm{p}=0.250\end{array}$ \\
\hline Roland Morris score & $10(6,15) 1,22$ & $5(1,12) 0,23$ & $-3(-7,0)-20,12 * * *$ & $\begin{array}{l}\text { Wilcoxon } \\
\mathrm{p}<0.0001\end{array}$ \\
\hline Oswestry Disability Index & $40(28,56) 6,92^{*}$ & $22(12,40) 0,82 * *$ & $-10(-26,-2)-80,30^{\wedge \wedge}$ & $\begin{array}{l}\text { Wilcoxon } \\
\mathrm{p}<0.0001\end{array}$ \\
\hline EQ5D5L utility & $0.68(0.48,0.79)-0.17,0.94$ & $0.83(0.67,0.89)-0.03,1.00$ & $0.07(0,0.23)-0.32,0.80 * * *$ & $\begin{array}{c}\text { Paired t-test } \\
\mathrm{p}<0.0001\end{array}$ \\
\hline $\begin{array}{l}\text { Oswestry Disability } \\
\text { Index } \leq 22\end{array}$ & $14(18 \%)^{*}$ & $35(51 \%)$ & & $\begin{array}{l}\text { McNemar } \\
\mathrm{p}<0.0001\end{array}$ \\
\hline
\end{tabular}

Continuous variables expressed as: Median (IQR) range.

*1 patient did not respond; **2 patients did not respond; ***3 patients did not respond to both questionnaires; $\wedge 4$ patients did not respond to both questionnaires; $\wedge \wedge 6$ patients did not respond to both questionnaires. Outcome responses were the last of 6 or 12 month questionnaire.

\section{RESULTS}

One hundred and two patients were identified for the Inversion Registry. Figure 2 shows the Study flow chart for this registry. Of 102 patients referred to the study Physiotherapist, 9 did not attend. The study Physiotherapist assessed 93 patients and 8 were found to be ineligible.

They were aged 20 to 78, median 47 years. They were experiencing high pain levels on the day of this initial assessment.

Following 6 treatment sessions in clinic, patients were offered a table at home and 81 took up this offer. Four did not, either because they could not tolerate the inversion and wanted surgery as soon as possible or because they had no room for the table at home. Two of these had surgery. A further 5 patients returned the inversion table after a short time because of a lack of space at home and/or no further need.

Table 3 also shows the status of the 66 patients who returned to clinic at six weeks for assessment by the physiotherapist. It shows that patients reported lower levels of pain at this time.

Table 2 shows the responses to the pre-treatment self-completed questionnaires indicating the level of disability prior to treatment for the 77 who returned the questionnaire.

Not all patients returned both their 6 and 12-month outcome self-assessment questionnaires but in total a response was obtained from 70 patients at one or both time points. Responses were obtained at both time points from 38, at 6 months only from 23 and from 9 at 12 months only. The patients who completed a 6-month but not a 12-month questionnaire were contacted by phone and they reported no change in status compared with that at 6 months.

Of the 85 patients recruited to the study 18 (21\%) had surgery within 24 months (14 within 12 months of recruitment) (Fig. 3). In addition, of the 8 patients assessed by the Physiotherapist as "not eligible for inversion therapy" 2 had surgery during the year. A further investigation, up to 31st March 2018, of time to surgery, found that no further registry patients had undergone surgery. The time to surgery varied between 64 and 716 days with a median of 230 days.

Of the 70 patients returning an outcome self-assessment questionnaire there appeared to be improvements in median VAS, RM, ODI and Health Utility compared with the pre-treatment questionnaire. Table 2 shows the values on these measures at outcome and the change from baseline. Three quarters of the patients $(49 / 66,74 \%)$ had a lower pain score at follow-up and 12\% (8/66) had no change. Similarly, 75\% (48/64) had an improvement in Oswestry Disability Index and 69\% (46/67) showed an improvement on Roland Morris score.

Of the 70 patients who returned an outcome questionnaire 12 had surgery; of the 15 who did not, 6 had surgery.

For the waiting list controls from 2014, the initial file contained 628 entries and the admissions file 679 entries. After cleaning there were 540 cases in the dataset varying in age from 18 to 84 with a median age of 52 and 517 (96\%) had surgery within 12 months of being put on the waiting list. The time to surgery varied between 0 and 369 days with a median of 109 days (Fig. 3).

For the matched controls 3 were identified (see methods) for each of 78 remaining registry patients. The electronic record was searched for operation notes for these controls up to 31 March 2018. There were 126 cases in the dataset varying in age 


\section{Study flow chart}

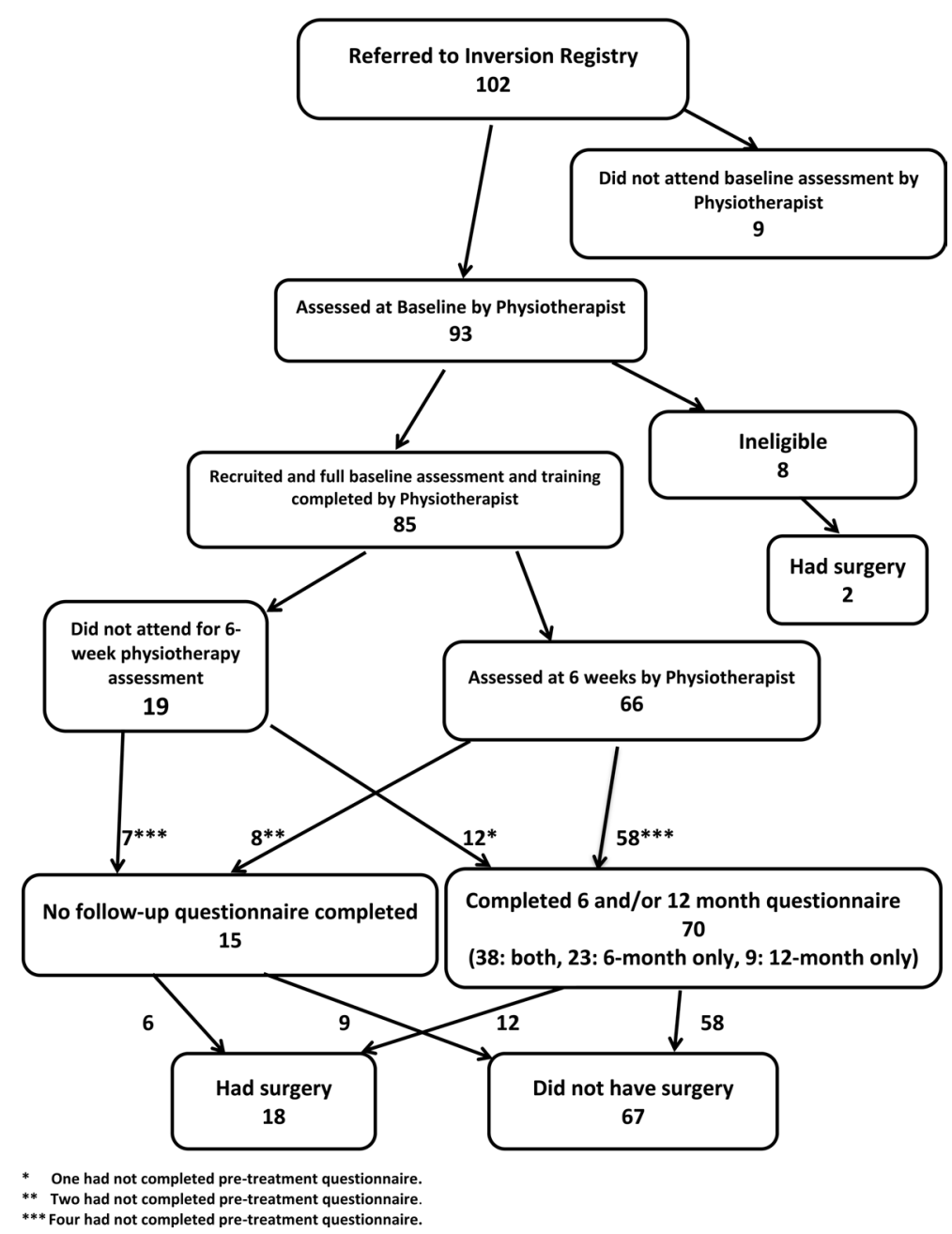

Fig. 2. Study flow chart showing patients as they were assessed in the registry and their pathway through the study to show operative interventions.

from 19 to 79 with a median age of 47 and 54 patients (43\%) had surgery by the end of the follow up period, 49 patients (39\%) within 2 years. The time to surgery varied between 1 and 1,458 days with a median of 116 days (Fig. 3).

\section{DISCUSSION}

This study suggests inversion therapy reduces symptoms and the rate of surgery in patients with lumbar disc disease and sciatica. The comparative groups were made up of contemporaneously collected patients with the same symptoms during the same year (2014). During that and subsequent years $43 \%$ of patients with leg pain and/or sciatica underwent invasive open operations. By contrast, only 14 of the 85 patients having inversion therapy (16\%) underwent surgery within 1 year and $21 \%$ within 2 years. This rate of surgery in the inversion group confirms the rate seen in the pilot PRCT (22\%). This compares favourably with the $78 \%$ rate of surgery seen in control patients in that trial ${ }^{1)}$ and the $43 \%$ rate seen in the matched controls reported here (Fig. 3).

After inversion treatment, we also saw improvement in the pain and disability measures in the registry patients, who acted as their own controls for this part of the study. The median VAS at clinic assessment was 7 at baseline, 2 at six weeks and 3 at outcome according to the self-completed questionnaires. The baseline questionnaire VAS pain score reduced from 6 at pre-treatment to 3 at outcome even though this was months after clinic attendances had finished. The median ODI fell from 40 to 22 and the median RM from 10 to 5. More than $75 \%$ of patients showed an improvement over the time period.

The main limitation of the study is that patients were not randomised. The control group was planned to have 2 matched controls for each patient, but occasionally only 1 patient could be matched. Also, case selection in the registry was made 
Table 3. Status at initial and six-week assessment

\begin{tabular}{|c|c|c|}
\hline & $\begin{array}{l}\text { Baseline assessment } \\
\qquad \mathrm{N}=85\end{array}$ & $\begin{array}{c}\text { Six-week assessment } \\
\mathrm{N}=66\end{array}$ \\
\hline Age (Median, IQR, Range) & $47(39,58) 20,78$ & $47(40,56) 22,78$ \\
\hline Male $(\%)$ & $39(46 \%)$ & $28(42 \%)$ \\
\hline Visual analogue pain score (Median, IQR, Range) & $7(5,7) 0,10$ & $2(0,5) 0,10$ \\
\hline \multicolumn{3}{|l|}{ Symptoms } \\
\hline Backpain (\%) & $73(86 \%)$ & $33(50 \%)$ \\
\hline Sciatica (\%) & $60(71 \%)$ & $21(32 \%)$ \\
\hline \multicolumn{3}{|l|}{ Side } \\
\hline Right (\%) & $27(32 \%)$ & $15(23 \%)$ \\
\hline Left $(\%)$ & $25(29 \%)$ & $8(12 \%)$ \\
\hline Both $(\%)$ & $16(19 \%)$ & $5(8 \%)$ \\
\hline None/Not Recognised (\%) & $17(20 \%)$ & $38(58 \%)$ \\
\hline \multicolumn{3}{|l|}{ Tests-straight leg raise } \\
\hline Normal (\%) & $17(20 \%)$ & $29(44 \%)$ \\
\hline Reduced (\%) & $67(79 \%)$ & $37(56 \%)$ \\
\hline Unable to test (\%) & $1(1 \%)$ & \\
\hline \multicolumn{3}{|l|}{ Tests-myotomes } \\
\hline Reduced (\%) & $29(34 \%)$ & $18(27 \%)$ \\
\hline Normal (\%) & $45(53 \%)$ & $48(73 \%)$ \\
\hline Not Recorded (\%) & $11(13 \%)$ & \\
\hline \multicolumn{3}{|l|}{ Tests-reflexes } \\
\hline Normal (\%) & $44(52 \%)$ & $41(62 \%)$ \\
\hline Diminished (\%) & $31(37 \%)$ & $22(33 \%)$ \\
\hline Absent $(\%)$ & $2(2 \%)$ & $2(3 \%)$ \\
\hline Unable to test (\%) & $1(1 \%)$ & \\
\hline Not Recorded (\%) & $7(8 \%)$ & $1(2 \%)$ \\
\hline \multicolumn{3}{|l|}{ Dermatomes } \\
\hline Normal (\%) & $32(38 \%)$ & $40(61 \%)$ \\
\hline Diminished (\%) & $41(48 \%)$ & $26(39 \%)$ \\
\hline Unable to test (\%) & $1(1 \%)$ & \\
\hline Not Recorded (\%) & $11(13 \%)$ & \\
\hline
\end{tabular}

Continuous variables expressed as: Median (IQR) range for age and Visual Analogue Scores.

by only four of the neurosurgeons in the unit, while the control group came from all twelve neurosurgeons in the unit. The surgical waiting list criteria are broadly similar for all neurosurgeons but the inclusion criteria for the registry were specific and may also represent a bias. Nevertheless, the overall 12-month lumbar disc surgery rate for similar patients put onto the neurosurgical waiting list in 2014 was $96 \%$ : much higher than in the matched pairs control group (Fig. 3).

Inversion Therapy has been practiced for thousands of years ${ }^{8,9}$. Inversion therapy was again published as an effective treatment by Sheffield ${ }^{13)}$ in 1964 and since then numerous studies have referred to the use of inversion as an effective form of traction to produce lumbar disc distraction of up to $4 \mathrm{~mm}$ at each disc space, mainly at L3/4 and L4/5 ${ }^{14-16)}$.

In a separate study, sixty percent body weight traction load was required to reduce the intra disc pressure by $25 \%{ }^{17)}$.

Inversion uses gravity to produce a traction force that is much larger than that which can be achieved on conventional horizontal traction tables. Beurskens et al. performed a randomised clinical trial ${ }^{18)}$, which regarded less than $25 \%$ of the body weight as low dose traction while $35 \%$ to $50 \%$ of body weight was what they called real traction. However, that trial, which showed no benefit from inversion, was in patients with non-specific back pain rather than MRI-proven disc protrusion with sciatica, as in our study. By contrast, in patients with lumbar disc protrusions, mechanical lumbar traction (not inversion) was effective at improving the Oswestry Disease Index in patients using a 5 point predictive scoring system ${ }^{19}$. Similarly, mechanical lumbar traction in patients with low back and leg pain due to nerve root compression produced greater improvements in disability and fear avoidance beliefs at 2 weeks but not at 6 weeks compared with controls ${ }^{20)}$. However, in a PRCT involving similar patients, Thackeray et al. showed that mechanical lumbar traction did not improve outcome compared with an extension orientated treatment approach ${ }^{21)}$. Hahne et al. systematically reviewed traction with lumbar disc herniation in 2010 and found that there was no benefit ${ }^{22}$. 


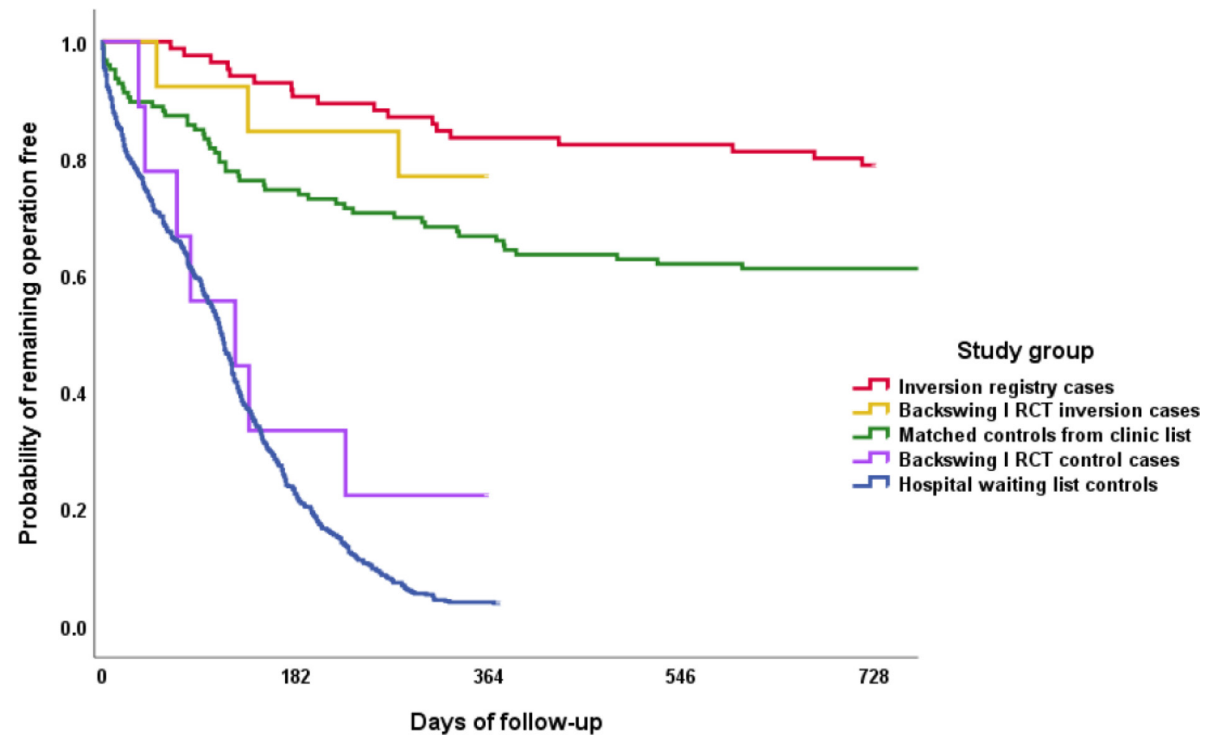

Fig. 3. Probability of remaining surgery free in the inversion registry vs. Matched controls from clinic list (Logrank test $\mathrm{p}<0.001)$. Backswing I Inversion cases and controls from the previous PRCT (1). Hospital waiting list controls from the Neurosurgery lumbar spine operative waiting list in 2014, followed through to 2015.

Cheng et al. also performed a systematic review and meta-analysis about the effect of mechanical traction and showed a significant short-term benefit but there was no long-term benefit ${ }^{23}$. Neither of these 2 systematic reviews of traction included inversion therapy.

The existing small published $\mathrm{PRCT}^{1)}$ and this current case-controlled study demonstrate a reduced need for surgery compared with controls. Also, in the inverted patients, their symptoms were significantly less severe than they were before the inversion therapy. Our study makes a strong case for setting up a large PRCT of inversion therapy for these patients.

The forces that gravity exerts during inversion in patients with lumbar disc protrusions relieved their symptoms and avoided the need for surgery.

\section{Conflicts of interest}

The funding for the administrator of the study was supplied by Teeter International Ltd. as were the inversion tables. The study, its conception, analysis, interpretation and submission for publication occurred completely independently of this sponsor.

\section{ACKNOWLEDGEMENTS}

This study was supported by Newcastle University, the Newcastle Neurosurgery Foundation Ltd. and Teeter International Ltd. All inversion tables were provided by Teeter.

\section{REFERENCES}

1) Prasad KS, Gregson BA, Hargreaves G, et al.: Inversion therapy in patients with pure single level lumbar discogenic disease: a pilot randomized trial. Disabil Rehabil, 2012, 34: 1473-1480. [Medline] [CrossRef]

2) Vos T, Lim SS, Abbafati C, et al. GBD 2019 Diseases and Injuries Collaborators: Global burden of 369 diseases and injuries in 204 countries and territories, 1990-2019: a systematic analysis for the Global Burden of Disease Study 2019. Lancet, 2020, 396: 1204-1222. [Medline] [CrossRef]

3) Vos T, Flaxman AD, Naghavi M, et al.: Years lived with disability (YLDs) for 1160 sequelae of 289 diseases and injuries 1990-2010: a systematic analysis for the Global Burden of Disease Study 2010. Lancet, 2012, 380: 2163-2196. [Medline] [CrossRef]

4) Ashworth J, Konstantinou K, Dunn KM: Prognostic factors in non-surgically treated sciatica: a systematic review. BMC Musculoskelet Disord, 2011 , 12 : 208. [Medline] [CrossRef]

5) Konstantinou K, Dunn KM: Sciatica: review of epidemiological studies and prevalence estimates. Spine, 2008, 33: 2464-2472. [Medline] [CrossRef]

6) Weir S, Samnaliev M, Kuo TC, et al.: The incidence and healthcare costs of persistent postoperative pain following lumbar spine surgery in the UK: a cohort study using the Clinical Practice Research Datalink (CPRD) and Hospital Episode Statistics (HES). BMJ Open, 2017, 7: e017585. [Medline] [CrossRef] 
7) van Tulder MW, Koes BW, Bouter LM: A cost-of-illness study of back pain in The Netherlands. Pain, 1995, 62: 233-240. [Medline] [CrossRef]

8) Vasiliadis ES, Grivas TB, Kaspiris A: Historical overview of spinal deformities in ancient Greece. Scoliosis, 2009, 4: 6. [Medline] [CrossRef]

9) Vidius V: Chirurgia e Graeco in Latinum conversa, Vido Vidio Florentino interprete, cum nonnullis eiufdem Vidij comentarijs. Excudebat Petrus Gallerius, 1544, Comment III: 179.

10) Roland M, Morris R: A study of the natural history of back pain. Part I: development of a reliable and sensitive measure of disability in low-back pain. Spine, 1983, 8: 141-144. [Medline] [CrossRef]

11) van Hooff ML, Mannion AF, Staub LP, et al.: Determination of the Oswestry Disability Index score equivalent to a "satisfactory symptom state" in patients undergoing surgery for degenerative disorders of the lumbar spine—a Spine Tango registry-based study. Spine J, 2016, 16: 1221-1230. [Medline] [CrossRef]

12) Devlin N, Shah K, Feng Y, et al.: Valuing health related quality of life: an EQ-5D-5L value set for England. Health Economics, 2018, 27 : 7-22.

13) Sheffield FJ: Adaptation of tilt table for lumbar traction. Arch Phys Med Rehabil, 1964, 45: 469-472. [Medline]

14) Gianakopoulos G, Waylonis GW, Grant PA, et al.: Inversion devices: their role in producing lumbar distraction. Arch Phys Med Rehabil, 1985, 66: 100-102. [Medline]

15) Kane MD, Karl RD, Swain JH: Effects of gravity-facilitated traction on intervertebral dimensions of the lumbar spine. J Orthop Sports Phys Ther, 1985, 6: 281-288. [Medline] [CrossRef]

16) Vernon H: Inversion therapy: a study of physiological effects. J CCA, 1985, 29: 138-140.

17) Nachemson A, Elfström G: Intravital dynamic pressure measurements in lumbar discs. A study of common movements, maneuvers and exercises. Scand J Rehabil Med Suppl, 1970, 1: 1-40. [Medline]

18) Beurskens AJ, de Vet HC, Köke AJ, et al.: Efficacy of traction for nonspecific low back pain. 12-week and 6-month results of a randomized clinical trial. Spine, 1997, 22: 2756-2762. [Medline] [CrossRef]

19) Hirayama K, Tsushima E, Arihara H, et al.: Developing a clinical prediction rule to identify patients with lumbar disc herniation who demonstrate short-term improvement with mechanical lumbar traction. Phys Ther Res, 2019, 22: 9-16. [Medline] [CrossRef]

20) Fritz JM, Lindsay W, Matheson JW, et al.: Is there a subgroup of patients with low back pain likely to benefit from mechanical traction? Results of a randomized clinical trial and subgrouping analysis. Spine, 2007, 32: E793-E800. [Medline] [CrossRef]

21) Thackeray A, Fritz JM, Childs JD, et al.: The effectiveness of mechanical traction among subgroups of patients with low back pain and leg pain: a randomized trial. J Orthop Sports Phys Ther, 2016, 46: 144-154. [Medline] [CrossRef]

22) Hahne AJ, Ford JJ, McMeeken JM: Conservative management of lumbar disc herniation with associated radiculopathy: a systematic review. Spine, 2010, 35: E488-E504. [Medline] [CrossRef]

23) Cheng YH, Hsu CY, Lin YN: The effect of mechanical traction on low back pain in patients with herniated intervertebral disks: a systemic review and metaanalysis. Clin Rehabil, 2020, 34: 13-22. [Medline] [CrossRef] 